\title{
ESTUDO DO PROCESSO DE PURIFICAÇÃO DE BIODIESEL DE CANOLA POR ADSORÇÃO EM CARVÃO ATIVADO
}

\author{
T. R. SPARTALIS ${ }^{1}$, M. OLIVEIRA ${ }^{1}$, N.C. PEREIRA ${ }^{1}$ e M. F. VIEIRA ${ }^{1}$ \\ ${ }^{1}$ Universidade Estadual de Maringá, Departamento de Engenharia Química \\ E-mail para contato: t.rossi1895@gmail.com
}

\begin{abstract}
RESUMO - O uso dos combustíveis fósseis como fonte de energia e a contínua procura por fontes alternativas, levaram à utilização do biodiesel como substituto ao diesel do petróleo. O biodiesel é produto da reação de transesterificação de um óleo vegetal ou gordura animal com um álcool de cadeia curta, formando ésteres etílicos ou metílicos e glicerol. A Agência Nacional de Petróleo Gás Natural e Biocombustíveis - ANP, determina. para o biodiesel. um teor máximo de $0,02 \%$ de glicerol livre. A purificação convencional, para separar o glicerol do éster, utiliza grandes quantidades de água, aumentando a geração de efluentes. Assim este trabalho propõe um processo alternativo de purificação utilizando adsorção em carvão ativado. Para tanto foi realizada a análise da cinética e das isotermas de adsorção para o biodiesel de óleo de canola e etanol. As amostras foram purificadas variando tempo e concentração de adsorvente. Os resultados mostraram que a reação atingiu o equilíbrio em 60 minutos e o modelo matemático que melhor se ajustou aos dados da cinética foi o de pseudo-primeira ordem e para as isotermas de equilíbrio foi o de Freundlich. O processo de purificação do biodiesel via adsorção em carvão ativado mostrou ser um método alternativo com baixo tempo de equilíbrio. As isotermas apresentam perfil favorável à remoção da glicerina livre presente na solução. O teor de glicerol final no biodiesel foi de $0,019 \%$ que é abaixo do limite estabelecido pela ANP.
\end{abstract}

\section{INTRODUÇÃO}

A procura por fontes alternativas de produção de energia é um dos ramos mais ativos na pesquisa cientifica. Além do problema futuro de insuficiência energética cientistas alertam sobre o aquecimento global, cuja principal causa é a queima de combustíveis de origem não renovável, gerando gases que intensificam o efeito estufa (CARVALHO, 2006). A utilização de óleos vegetais e gordura animal para reações de transesterificação e consequente produção de biodiesel tem grande potencial econômico e financeiro, visto que o produto dessa reação pode ser considerado um biocombustível. Segundo Almeida de Paula et al (2011), para a utilização do biodiesel em motores ele deve estar isento de impurezas que possam se acumular nos bicos injetores, provocar danos à câmara de combustão ou a outras partes dos motores.

\subsection{O Biodiesel}

O biodiesel é obtido da reação de transesterificação entre um óleo vegetal ou gordura animal e um álcool de cadeia curta (metanol ou etanol). Além de uma mistura de ésteres a 
reação também produz o glicerol e impurezas. O Brasil possui um programa bem sucedido e estabelecido para o etanol que está diretamente ligado à produção de biodiesel (Silva, 2009). Mesmo quando este biocombustível é produzido com óleo degomado, são necessários métodos de purificação eficazes, para que o biodiesel final atenda às especificações da Agência Nacional do Petróleo, Gás Natural e Biocombustíveis (ANP, 2010). O método de purificação geralmente utilizado, a lavagem úmida, possui desvantagens como a geração de um grande volume de efluentes e formação de emulsões (Costa, 2010). Além disso, o trabalho de Costa (2010) mostra que o uso do etanol aumenta a formação de emulsões durante a lavagem aquosa, o que faz com que a mistura precise passar por nova etapa de separação, usualmente a centrifugação, ocasionando ainda mais gastos na produção.

\subsection{A Adsorção}

A adsorção é uma técnica que é utilizada em vários processos industriais como tratamento de água, indústria petroquímica, biotecnologia, entre outras. Ela envolve a separação de uma substância de uma fase, acompanhada pelo seu acúmulo ou concentração na superfície de um sólido, (Golin (2007). Com a finalidade de estimar a capacidade de adsorção dinâmica é necessário ter a informação sobre o equilíbrio de adsorção. O carvão ativado é um dos adsorventes mais utilizados industrialmente e sua obtenção provém da decomposição térmica de materiais ricos em carbono.

\subsection{Cinética e Isoterma de adsorção}

A cinética de adsorção busca obter uma relação entre a quantidade adsorvida de soluto em função do tempo, desta forma, a cinética possibilita a obtenção do tempo de equilíbrio no qual não há mais variação significativa na adsorção com um acréscimo ou decréscimo de tempo. As isotermas de adsorção são descritas através de modelos matemáticos, alguns com base na simplicidade da adsorção e dessorção e outros em modelos empíricos, (Suzuki, 1989). As equações das isotermas de Langmuir e Freundlich são os dois modelos mais usados para descrever o equilíbrio na adsorção, (Suffet e McGuire, 1980).

Portanto este trabalho busca analisar o processo de adsorção do glicerol, presente no biodiesel, com carvão ativado, interpretando os resultados da cinética e isoterma de adsorção e comparando com a literatura.

\section{MATERIAIS E MÉTODOS}

A produção de biodiesel foi realizada em um balão de três bocas imerso em um banhomaria, com a temperatura controlada em $45^{\circ} \mathrm{C}$. A razão molar óleo:etanol de 1:7,5 e a quantidade de catalisador de $1 \%$ de percentual mássico em relação ao óleo de canola. A mistura permaneceu durante o período de 1 hora a uma rotação de 300rpm. Após o período reacional, o biodiesel produzido foi levado a um roto-evaporador sob vácuo a temperatura de $65^{\circ} \mathrm{C}$, para que ocorra a recuperação do etanol não reagido.

Os ensaios de adsorção para a determinação da cinética e das isotermas de adsorção, foram realizados com amostras de $10 \mathrm{~g}$ da mistura reacional, após a recuperação do etanol em erlenmeyers de $150 \mathrm{~mL}$, variando a massa do carvão ativado e mantidos em agitação com o auxílio de um shaker. 
As isotermas de adsorção foram obtidas variando a concentração do adsorvente a temperatura constante de $65^{\circ} \mathrm{C}$ em um shaker durante 300 minutos.

\section{RESUTADOS E DISCUSSÃO}

A cinética foi realizada em ensaios de adsorção onde era variado o tempo de permanência do adsorvente em contato com a solução. No períodos de 1 minuto a 300 minutos, foi determinada a relação entre tempo de adsorção e a remoção do glicerol da solução. Os ensaios também foram realizados em três diferentes temperaturas: 25,40 e $65^{\circ} \mathrm{C}$. Os resultados estão apresentados na Figura 1.

Figura 1 - Cinética de adsorção

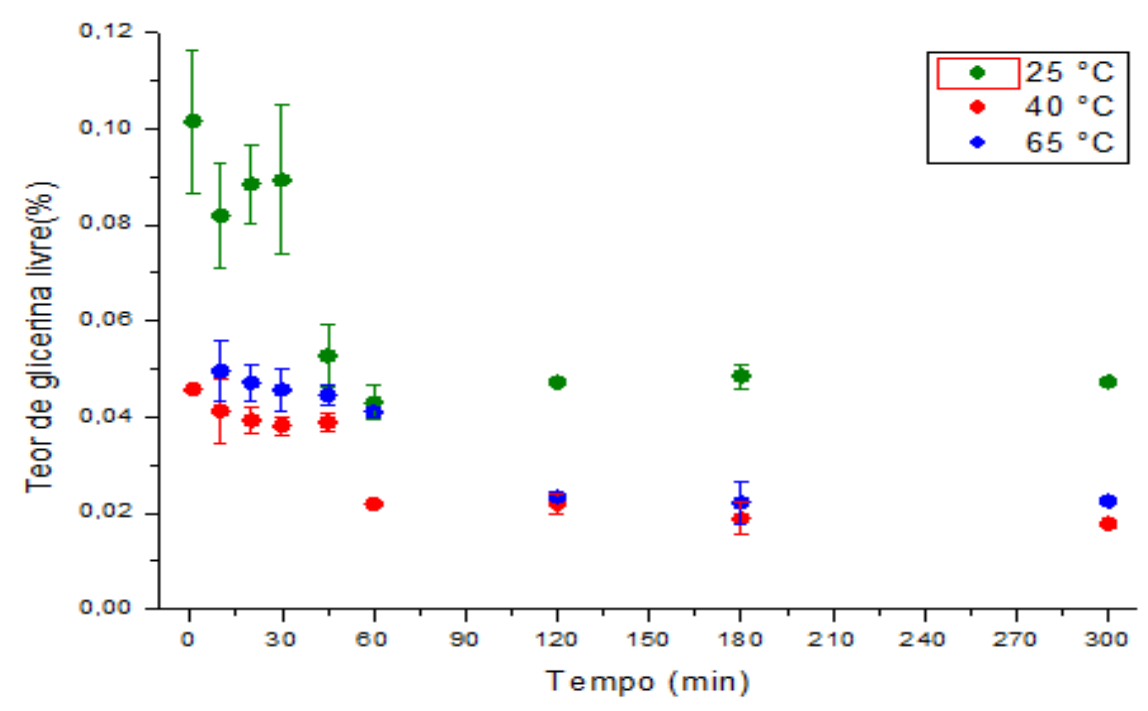

A adsorção da glicerina livre do biodiesel, utilizando carvão ativado, mostrou potencial deste processo, pois os resultados da cinética de adsorção demonstram a grande remoção do glicerol presente em solução nas temperaturas de 40 e $65^{\circ} \mathrm{C}$, atingindo nos melhores resultados 0,019\%, um valor abaixo do limite de 0,02, estabelecido pela ANP.

O aumento da temperatura do processo de adsorção da glicerina promove maior remoção do glicerol, além disso, o equilíbrio é atingido completamente em torno de 60 minutos. $\mathrm{O}$ fato de em temperaturas mais altas a remoção ser maior deve-se a que a glicerina tem sua viscosidade diminuída com o aumento da temperatura, ou seja, facilita o processo de difusão do adsorvato para o interior dos poros.

Para melhor avaliação da cinética de adsorção foram analisados modelos pré-existentes: Modelo de pseudo primeira ordem e modelo de pseudo segunda ordem. Ambos os modelos relacionam a quantidade adsorvida em um determinado tempo em relação às diferenças entre concentrações do glicerol no equilíbrio e no momento " $t$ ". Para os modelos de primeira ordem essa relação é linear, enquanto o modelo de pseudo segunda ordem essa relação é quadrática. Os resultados da comparação entre os modelos são apresentados nas Tabelas 1 e 2. 
Tabela 1 - Ajuste ao modelo de pseudo primeira ordem

\begin{tabular}{|c|c|c|c|}
\hline Temperatura & Parâmetro & Valor & Erro \\
\hline \hline \multirow{3}{*}{$25^{\circ} \mathrm{C}$} & $\mathrm{Qe}$ & 0,26602 & 0,0033 \\
\cline { 2 - 4 } & $\mathrm{K} 1$ & 2,61989 & 0,5117 \\
\cline { 2 - 4 } & $\mathrm{R}^{2}$ & 0,98766 & -------- \\
\hline \multirow{3}{*}{$40^{\circ} \mathrm{C}$} & $\mathrm{Qe}$ & 0,28237 & 0,00166 \\
\cline { 2 - 4 } & $\mathrm{K} 1$ & 3,58846 & 0,64159 \\
\cline { 2 - 4 } & $\mathrm{R}^{2}$ & 0,99723 & ------- \\
\hline \multirow{3}{*}{$65^{\circ} \mathrm{C}$} & $\mathrm{Qe}$ & 0,28026 & 0,00185 \\
\cline { 2 - 4 } & $\mathrm{K} 1$ & 3,60732 & 0,73282 \\
\cline { 2 - 4 } & $\mathrm{R}^{2}$ & 0,99652 & ------- \\
\hline
\end{tabular}

Tabela 1 - Ajuste ao modelo de pseudo segunda ordem

\begin{tabular}{|l|l|l|l|}
\hline Temperatura & Parâmetro & Valor & Erro \\
\hline \multirow{4}{*}{$25^{\circ} \mathrm{C}$} & qe & 0,26696 & 0,00326 \\
\cline { 2 - 4 } & $\mathrm{K} 2$ & 41,532 & 19,919 \\
\cline { 2 - 4 } & $\mathrm{R}^{2}$ & 0,98891 & -------- \\
\hline \multirow{4}{*}{$40^{\circ} \mathrm{C}$} & qe & 0,28276 & 0,00165 \\
\cline { 2 - 4 } & $\mathrm{K} 2$ & 106,652 & 59,735 \\
\cline { 2 - 4 } & $\mathrm{R}^{2}$ & 0,99746 & ------- \\
\hline \multirow{3}{*}{$65^{\circ} \mathrm{C}$} & qe & 0,28067 & 0,00184 \\
\cline { 2 - 4 } & $\mathrm{K} 2$ & 170,256 & 67,478 \\
\cline { 2 - 4 } & $\mathrm{R}^{2}$ & 0,99679 & -------- \\
\hline
\end{tabular}

Os erros observados para o ajuste ao modelo de pseudo segunda ordem são maiores do que os erros do modelo de pseudo primeira ordem. Dessa forma definimos que o modelo que melhor se ajustou a cinética de adsorção foi o modelo de pseudo primeira ordem.

As isotermas de adsorção representa a segunda analise a ser verificada no processo de adsorção estudado. O processo consiste na variação da concentração do carvão ativado na solução e avaliar a remoção do glicerol em cada concentração. De fato, a isoterma de adsorção busca avaliar a capacidade de adsorção do adsorvente, para isso foi feito também ajustes da isoterma obtida relacionando-a com modelos já existentes. Os resultados estão representados na Figura 2.

Figura 2 - Isotermas de adsorção 


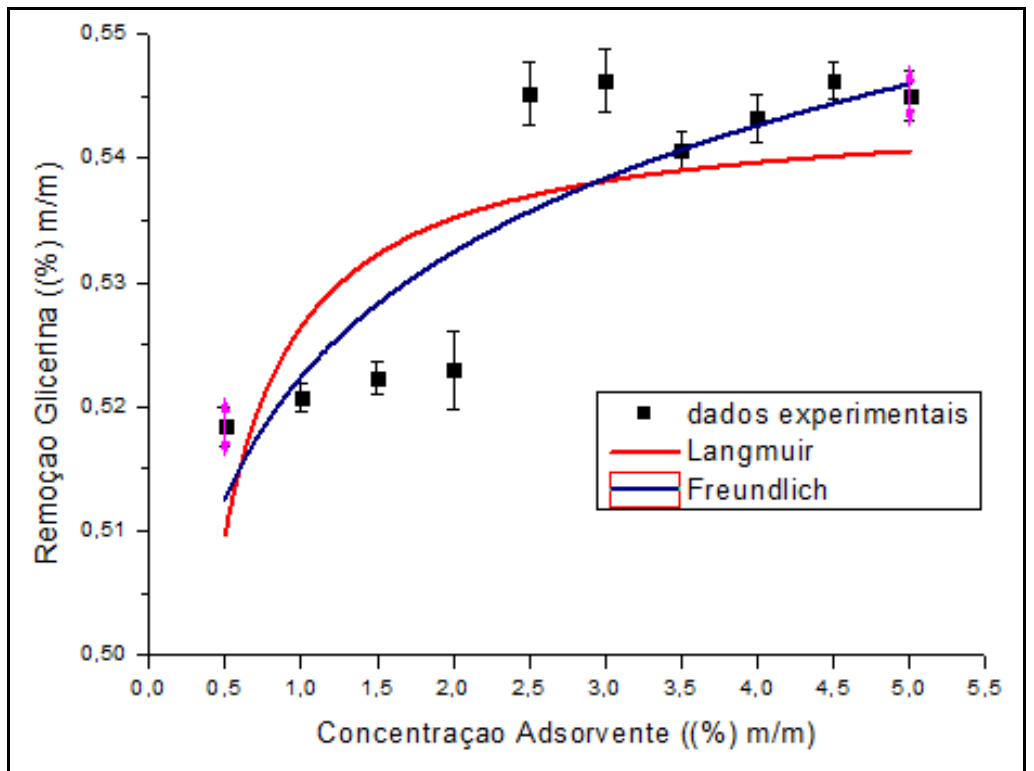

É visível um perfil côncavo da curva obtida graficamente, esse perfil é considerado favorável visto que, pequenas quantidades de adsorvente conseguem reter em sua superfície grandes quantidades de soluto. Para uma melhor avaliação desse processo são utilizados modelos matemáticos que permitem realizar uma análise comparativa dos resultados. Foram ajustados os modelos de Langmuir e Freundlich aos dados experimentais. Estes modelos são representados pelas equações 1 e 2 respectivamente.

$$
\begin{aligned}
& \mathrm{q}_{\mathrm{eq}}=\frac{q m \cdot K \cdot C e}{1+K \cdot C e} \\
& \mathrm{Q}_{\mathrm{e}}=K \cdot C e^{1 / n}
\end{aligned}
$$

Os resultados do ajuste estão representados na Tabela 3.

Tabela 3 - Ajuste aos modelos de Langmuir e Freundlich

\begin{tabular}{|l|c|r|r|}
\hline \multirow{2}{*}{ Isoterma } & \multirow{2}{*}{ Parâmetros } & \multicolumn{2}{|c|}{ Biodiesel óleo de canola } \\
\cline { 3 - 4 } & & & \multicolumn{1}{c|}{ Erro } \\
\hline \hline \multirow{3}{*}{ Langmuir } & $\mathrm{Q}_{m}$ & 0,54426 & 0,00417 \\
\cline { 2 - 4 } & $\mathrm{K}$ & 29,50023 & 8,06706 \\
\cline { 2 - 4 } & $\mathrm{r}^{2}$ & 0,59892 & ------------ \\
\hline \multirow{3}{*}{ Freundlich } & $\mathrm{K}$ & 0,5224 & 0,0021 \\
\cline { 2 - 4 } & $\mathrm{n}$ & 36,40898 & 5,32766 \\
\cline { 2 - 4 } & $\mathrm{r}^{2}$ & 0,83728 & ----------- \\
\hline
\end{tabular}


Os parâmetros encontrados e a análise dos ajustes das curvas para ambos os modelos mostram que o modelo de Freundlich melhor se ajustou as isotermas de adsorção. Além disso, o parâmetro $\mathrm{r}^{2}$ no modelo de Langmuir está muito baixo. Portanto podemos afirmar que o modelo de Freundlich pode representar as isotermas obtidas no experimento.

O modelo de Freundlich prevê uma fisisorção e uma adsorção em multicamada, como pode ser constatado pela análise das isotermas obtidas experimentalmente.

\section{CONCLUSÕES}

Os resultados obtidos da cinética e das isotermas de adsorção nos permitem afirmar que o processo de purificação do biodiesel estudado é um processo eficiente, visto que remove de forma efetiva o glicerol presente em solução atingindo os padrões determinados pela ANP. A cinética de adsorção demonstrou que o sistema atinge o equilibro em torno dos 60 minutos e o modelo que melhor se ajustou foi o de pseudo primeira ordem.

As isotermas de adsorção obtidas comprovam a capacidade do carvão ativado de adsorver grandes quantidades de soluto com pequenas quantidades de adsorvente que é um fator importantíssimo em uma análise econômica. As isotermas também definiram que o modelo que melhor se ajustou aos dados experimentais foi o de Freundlich, confirmando uma fisisorção em multicamada. A fisisorção facilita a reutilização do carvão, visto que é um processo reversível.

\section{REFERÊNCIAS}

ALMEIDA DE PAULA, A. J.; KRUGEL, M.; MIRANDA, J. P.; ROSSI, L. F. S; COSTA NETO, P.R.Utilização de argilas para purificação de biodiesel. Quimica nova. V.34. p. 91-95. 2011.

CARVALHO, J. M. Biodiesel de soja - reação de transesterificação para aulas práticas de química orgânica. Química Nova, v. 30 p. 1369-1373, 2007

GOLIN, D. M. Remoção de chumbo de meios líquidos através de adsorção utilizando carvão ativado de origem vegetal e resíduos vegetais. Dissertação (Mestrado em engenharia ambiental). Universidade Federal do Paraná, Curitiba, 2007.

GOMES, M. C. S.; ARROYO, P. A.; PEREIRA, N. C. Influence of acidified water addition on the biodiesel and glycerol separation through membrane technology. Journal of Membrane Science. v. 431, p. 28-36, 2013.

SILVA, G. M.; QUADRI, M. B.; COSTA, A. E.; DIAS, R. Avaliação da remoção do glicerol livre do biodiesel por adsorção. Cobeqic. 2009.

SUFFET, I. H..; McGUIRE, M. J. Activated Carbon Adsorption of organics from Aqueous Phase. Volume 1. Ann Arbor Science. USA, 1980.

SUZUKI, M.; Adsorption Engineering, Kodansha, Japan, 1989. 